doi:10.1016/j.envpol.2005.07.015

Copyright (c) 2005 Elsevier Ltd All rights reserved.

\title{
Development and application of a sediment toxicity test using the benthic cladoceran Chydorus sphaericus
}

\section{T. Dekker ${ }^{a}$, G.D. Greve ${ }^{a, b}$, T.L. Ter Laak ${ }^{a, c}$, M.E. Boivin ${ }^{a, b}$, B. Veuger ${ }^{a, d}$, G. Gortzak $^{a}$, S. Dumfries ${ }^{a}$, S.M.G. Lücker ${ }^{a}$, M.H.S. Kraak ${ }^{a}$, W. Admiraal ${ }^{a}$ and H.G. van der Geest ${ }^{\mathrm{a}, *}$}

${ }^{a}$ Department of Aquatic Ecology \& Ecotoxicology, IBED, University of Amsterdam, Kruislaan 320, 1098 SM Amsterdam, The Netherlands

${ }^{b}$ Expert Centre for Substances, RIVM, P.O. Box 1, 3720 BA Bilthoven, The Netherlands

'IRAS, Utrecht University, Yalelaan 2, $3584 \mathrm{CL}$ Utrecht, The Netherlands

${ }^{\mathrm{d}}$ NIOO-KNAW, Centre for Estuarine and Marine Ecology, P.O. Box 140, 4400 AC

Yerseke, The Netherlands

* Corresponding author. Tel.: +31 20525 7721; fax: +31 205257716.

\section{Abstract}

This study reports on the development and application of a whole sediment toxicity test using a benthic cladoceran Chydorus sphaericus, as an alternative for the use of pelagic daphnids. A C. sphaericus laboratory culture was started and its performance under control conditions was optimised. The test was firstly validated by determining dose-response relationships for aqueous cadmium and copper and ammonia, showing a sensitivity of $C$. sphaericus ( $96 \mathrm{~h} \mathrm{LC} \mathrm{C}_{50}$ values of $594 \mu \mathrm{g} \mathrm{Cd} / \mathrm{L}, 191 \mu \mathrm{g} \mathrm{Cu} / \mathrm{L}$ and $46 \mathrm{mg}$ ammonia/L at pH 8) similar to that of daphnids. Next, sediment was introduced into the test system and a series of contaminated sediments from polluted locations were tested. A significant negative correlation between survival and toxicant concentrations was observed. It is concluded that the test developed in the present study using the benthic cladoceran $C$. sphaericus is suitable for routine laboratory sediment toxicity testing.

\section{Introduction}

During the past few decades, water quality has generally improved (Admiraal et al., 1993), but sediments still contain high concentrations of xenobiotic compounds (Koelmans and Moermond, 2000). Therefore, sediments may act not only as a sink, but also as a source of a wide range of chemical substances, such as nutrients, metals, polychlorinated biphenyls (PCBs), and polycyclic aromatic hydrocarbons (PAHs), that have been deposited previously in high concentrations (Beurskens et al., 1993). Determining the effects of sediment bound toxicants on benthic biota is therefore a necessary step in ecological risk assessment. However, sediment toxicity is often tested by exposing Daphnia magna to pore water (Côté et al., 1998, Reinhold-Dudok van Heel and Den Besten, 1999 and Lahr et al., 2003). D. magna is not a benthic organism and isolated pore water may not reflect toxicant exposure in situ and thus may not provide reliable information on the impact of pollutants in sediments. Moreover, benthic animals are exposed to sediment bound toxicants in a different way than pelagic animals, due to e.g. ingestion and direct contact with the contaminated soil (Rönnpagel et al., 1998 and Sibly et al., 1999). Therefore we considered the use of benthic 
cladocerans (Chydoridae) which, unlike daphnids, can be tested in their natural micro-habitat, i.e. the sediment. Although their distribution is well studied (Duigan and Kovach, 1991, Whiteside et al., 1978 and Hann and Zrum, 1997), only few papers focus on aspects of the life history of chydorids (Keen, 1979, Robertson, 1988 and Dekker et al., 2002). The available information indicates that chydorids may be useful and sensitive test species (Koivisto et al., 1992, Dekker et al., 2002 and Bossuyt and Janssen, 2005).

One of the most common benthic cladoceran species is Chydorus sphaericus, a sediment dwelling species occurring in a variety of habitats (Duigan and Kovach, 1991, Fryer, 1995 and Van de Bund and Spaas, 1996), feeding mainly on detritus (Fig. 1). The abundance of chydorids in littoral regions of freshwater lakes makes them an important component of the aquatic ecosystem (Williams, 1982). They hold a key position in the food web by converting organic material into their own body mass that becomes in turn available for predators such as juvenile fish. This way their presence influences the transfer of chemicals in sediments and in the food chain. Hence, determining the effect of sediment bound toxicants on chydorids may be a good estimate for the potential effect of such contaminants on the benthic community. Being cladocerans, chydorids have the same advantages as daphnids for use in experiments, such as ease of handling and parthenogenetic reproduction. Therefore $C$. sphaericus may be a suitable species for standardized laboratory toxicity testing.

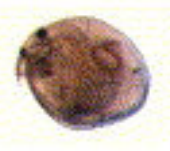

1

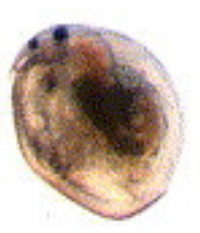

2

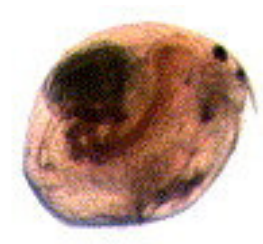

3

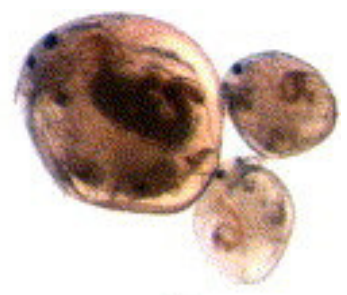

4

Fig. 1. Four developmental stages of $C$. sphaericus. Stage 1: neonate, stage 2: second instar with swollen ovaria, stage 3: third instar with eggs, stage 4: fourth instar with newly born neonates and swollen ovaria.

This study reports on the development and application of a sediment toxicity test using the benthic cladoceran $C$. sphaericus. In order to optimize the $C$. sphaericus laboratory culture and the control performance in the toxicity test, the influence of food type and temperature was analysed. The developed test, so far testing water exposure only, was validated by determining dose-response relationships for cadmium and copper that allowed comparison with Daphnia species which are often tested for these metals (Kluttgen and Ratte, 1994, Mark and Solbé, 1998 and Nebeker et al., 1986). In addition, the sensitivity of $C$. sphaericus to ammonia was determined, since ammonia toxicity is one of the most frequently occurring confounding factors in sediment toxicity tests (Lahr et al., 2003). Finally, sediment was introduced into the test system and this step was validated by subjecting the test to a series of contaminated sediments from polluted locations. 


\section{Materials and methods}

\subsection{C. sphaericus laboratory culture}

The clone of $C$. sphaericus used in this study was reared from one gravid female collected in the summer of 1998 in the Drontermeer, a eutrophic, sandy lake in The Netherlands.

The animals were kept in plastic containers $(\mathrm{I} \times \mathrm{w} \times \mathrm{h}=13 \times 8 \times 6 \mathrm{~cm})$ filled with $300 \mathrm{ml}$ of M7 medium (Elendt, 1990) and about $1 \mathrm{~g}$ of pre-combusted ( $3 \mathrm{~h}$ at $550^{\circ} \mathrm{C}$ ) quartz sand (Sibelco M32, Antwerp, Belgium; grain size $100 \mu \mathrm{m}-$ $400 \mu \mathrm{m})$. Three times a week, the animals were fed $2 \mathrm{ml}$ of a food suspension consisting of dried, ground nettle powder (Urtica dioica) $(0.5 \% \mathrm{w} / \mathrm{v})$ and $30 \times 10^{6} \mathrm{\mu m}^{3}$ Nitzschia perminuta/ml medium. Every week, around $70 \%$ of the culture medium was renewed, by decanting most of the medium from the container. Along with the medium, some of the animals in the culture were also removed. This partial removal prevented crowding which assured that the females continued to reproduce parthenogenetically and did not form ephippia. Every month each container was replaced by a new one that was inoculated by decanting part of the contents of an old container into it. The temperature in the culture room was maintained at $20^{\circ} \mathrm{C} \pm 1{ }^{\circ} \mathrm{C}$ and a light:dark regime of $16: 7 \mathrm{~h}$ with twice half hour twilight in between was applied.

\subsection{C. sphaericus test}

One day before the start of the experiment, adult females containing parthenogenetic eggs were taken from the culture and transferred into glass jars containing $75 \mathrm{ml}$ of medium and 5 drops of food suspension (see above). The jars were placed overnight in a climate room under the same culture conditions (see above). The next day, newborn neonates (0-24 h) were collected and used for the experiments.

All tests were performed at least in triplicate. The tests were carried out in small, round glass dishes $(3 \mathrm{ml}$ ) with a diameter of $3 \mathrm{~cm}$ and a depth of $7 \mathrm{~mm}$ with rounded edges to which $2 \mathrm{ml}$ of medium, 20 neonates and 1 drop of food suspension (see above) were added. The containers were loosely covered with a lid to prevent evaporation and the tests were performed under the same conditions as the culture (see above). After $96 \mathrm{~h}$ the animals were collected under a dissecting microscope and survival, growth and developmental stage were determined. Growth was calculated by subtracting the average initial length $(n=20)$ from the individual final length. Body length was measured with an image analyzer from the edge of the carapace above the nauplius eye to the posterior margin of the carapace where it splits. Developmental stage was determined by classifying the animals into the four stages as shown in Fig. 1, after which the mean developmental stage was calculated. In the sediment toxicity test $0.3 \mathrm{~g}$ of sediment was introduced into the test system and precombusted $\left(3 \mathrm{~h}\right.$ at $550^{\circ} \mathrm{C}$ ) quartz sand (Sibelco M32, Antwerp, Belgium; grain size $100 \mu \mathrm{m}-400 \mu \mathrm{m}$ ) was used as control sediment.

\subsection{Food and temperature}

The following food items were tested: ground Urtica powder, the fish foods Tetraphyll and Tetramin, a green alga (Selenastrum capricornutum), a diatom ( $N$. perminuta) and $N$. perminuta combined with $U$. dioica powder. The optimal quantities of these single food items had been determined in pilot experiments. The $U$. dioica powder, Tetraphyll and Tetramin were suspended in medium (1\% 
$\mathrm{w} / \mathrm{v}$ ) of which 2 drops were added to the test jars. The green alga was fed in a volume of $1 \times 10^{6} \mathrm{\mu m}^{3} / \mathrm{ml}$ and the diatom in a volume of $60 \times 10^{6} \mu \mathrm{m}^{3} / \mathrm{ml}$. These volumes were determined by using a Coulter Counter. The combination of $U$. dioica powder and $N$. perminuta was fed in quantities of $0.5 \% \mathrm{w} / \mathrm{v} U$. dioica suspension and a $N$. perminuta volume of $30 \times 10^{6} \mu \mathrm{m}^{3} / \mathrm{ml}$ medium, respectively, being half the amounts fed in the single food item treatments. The following temperatures were tested: $5,10,15,20$, and $25^{\circ} \mathrm{C}$. One-way analysis of variance (ANOVA) tests followed by Scheffe's post hoc test were conducted to test for significant differences between treatments and controls (Sokal and Rohlf, 1995).

\section{4. $\mathrm{Cu}, \mathrm{Cd}$ and ammonia toxicity}

Cadmium and copper were both added as chlorides, using a $1 \mathrm{~g} / \mathrm{l}$ stock solution. To measure the actual total metal concentrations in the water, two replicate samples $(0.5 \mathrm{ml})$ were taken at the start and at the end of the experiment. Since the test volume should be $2 \mathrm{ml}$ (see above), the experiments were initiated with $3 \mathrm{ml}$. The water samples were acidified with $20 \mu \mathrm{l} 70 \%$ nitric acid, centrifuged for $10 \mathrm{~min}$ at $3000 \mathrm{rpm}$ and transferred into new eppendorf vials. The samples were analysed by air-acetylene Flame Atomic Absorption Spectrometry (Perkin-Elmer 1100B, Norwalk, CT, USA) or by Furnace Atomic Absorption Spectrometry (Perkin-Elmer 5100PC/HGA600/AS60 equipped with Zeeman background correction, Norwalk, CT, USA). Quality of the metal analyses was ascertained by analyzing blanks and reference material (NIST:SRM 1643, National Institute of Standards and Technology, Gaithersburg, MD, USA). Survival, growth and developmental stage were plotted against the actual total metal concentration in the water. From these dose-response relationships, $\mathrm{EC}_{50}$ values and their corresponding $95 \%$ confidence limits were calculated using the log-logistic curve fitting procedure of Haanstra et al. (1985).

The ammonia toxicity test was performed in glass vials of $50 \mathrm{ml}$ to allow $\mathrm{pH}$ measurements with a relatively large $\mathrm{pH}$ electrode. One day prior to the experiments $20 \mathrm{ml}$ of aerated M7 Elendt medium was added to each vial. The $\mathrm{pH}$ of each vial was established at 8.0 by adding the $20 \mathrm{nM}$ buffer POPSO (disodiumsalt, Sigma), $\mathrm{NaOH}(0.01 \mathrm{M})$ and $\mathrm{HCl}(0.01 \mathrm{M})$. Total ammonia concentrations were set by adding $\mathrm{NH}_{4} \mathrm{Cl}$ from a stock solution of $150 \mathrm{mg} / \mathrm{L} \mathrm{NH} \mathrm{NH}_{4}$ in $\mathrm{M7}$ medium. The vials were placed in an incubator where the conditions were the same as during the metal toxicity experiments. Shortly before the start of the experiment, the $\mathrm{pH}$ was measured and adjusted if necessary. Before placing the test vials in the incubator and just before the experiment was terminated, $2 \mathrm{ml}$ of medium was taken from each test vial for analysis of the actual total ammonia concentration in the water, by means of a discrete analyzer for total ammonia. By means of a speciation model, the concentration of $\mathrm{NH}_{3}$ was determined for each treatment using the mean $\mathrm{pH}$ and total ammonia concentration. The model used for this purpose is described by Emmerson et al. (1975) and expresses the $\mathrm{NH}_{3}$ concentration as a fraction $(f)$ of the total ammonia concentration:

$$
f=1 / 10^{\mathrm{pK}}{ }_{\mathrm{a}}^{-\mathrm{pH}}+1
$$

where $\mathrm{p} K_{\mathrm{a}}=$ dissociation constant of $\mathrm{NH}_{4}{ }^{+}$, at $20^{\circ} \mathrm{C}$ in freshwater $(=9.407313106)$ and $\mathrm{pH}=$ mean $\mathrm{pH}$ during the experiment.

Survival was plotted against the actual total ammonia concentration and against the $\mathrm{NH}_{3}$ concentration in the water. From these dose-response relationships, $\mathrm{EC}_{10}$ and $\mathrm{EC}_{50}$ values and their corresponding $95 \%$ confidence limits were calculated using the log-logistic curve fitting procedure of Haanstra et al. (1985). 


\subsection{Sediment toxicity}

The sediment toxicity test using $C$. sphaericus was applied to a series of eight contaminated sediments and two controls, one with and one without sand. In addition, the following possible confounding factors were measured in a comparable separate setup: $\mathrm{pH}$ and the concentrations of $\mathrm{NO}_{2}{ }^{-}, \mathrm{NO}_{3}{ }^{-}$and $\mathrm{NH}_{4}{ }^{+}$. The sediments originated from a polluted brook in the centre of The Netherlands, De Wenumse Beek, contaminated by former copper mills, paper mills and other industries. $\mathrm{Cu}, \mathrm{Pb}, \mathrm{Cd}, \mathrm{Zn}$ and $\Sigma$ PAK [EPA 16] concentrations are given in Table 1. The sediments were homogenized and frozen at $-20^{\circ} \mathrm{C}$ in order to kill the autochthonous organisms. One day prior to the experiments the test vials were filled with $0.3 \mathrm{~g}$ sediment and $2 \mathrm{ml}$ medium. After $96 \mathrm{~h}$ the animals were handsorted from the sediments under a dissecting microscope and survival and growth were determined. A $t$-test was applied to test for significant differences between treatments and controls. To reduce the number of sediment variables, a principal component analysis was performed with the different concentrations of toxicants $(\mathrm{Pb}, \mathrm{Cd}, \mathrm{Cu}, \mathrm{Zn}$ and $\mathrm{PAH})$. The scores of the sediments on the first principal component served as a new variable for toxicant concentration (factor tox). It was tested if survival correlated with the factor tox using the Pearson correlation test.

Table 1.

Concentrations of $\mathrm{Cu}, \mathrm{Pb}, \mathrm{Cd}, \mathrm{Zn}$ and $\Sigma$ PAK [EPA 16] in sediments from the Wenumse Beek in $\mathrm{mg} / \mathrm{kg} \mathrm{dw}$

\begin{tabular}{|l|l|l|l|l|l|l|}
\hline Sample & $\mathbf{C u}$ & $\mathbf{P b}$ & $\mathbf{C d}$ & $\mathbf{Z n}$ & PAH & Factor tox \\
\hline Control & 0 & 0 & 0 & 0 & 0 & \\
\hline Sand Control & 0 & 0 & 0 & 0 & 0 & \\
\hline $\mathrm{A}$ & 30 & 47 & 0.52 & 50 & 1.20 & -0.48 \\
\hline $\mathrm{B}$ & 28 & 14 & $<0.4$ & 0.43 & 0.32 & -0.73 \\
\hline $\mathrm{C}$ & 190 & 32 & $<0.4$ & 37 & 3.10 & -0.55 \\
\hline $\mathrm{D}$ & 42 & 20 & $<0.4$ & 18 & 0.78 & -0.68 \\
\hline E & 240 & 140 & 0.63 & 170 & 4.6 & 0.09 \\
\hline F & 2400 & 400 & 1.3 & 360 & 30 & 2.14 \\
\hline G & 67 & 33 & $<0.4$ & 75 & 0.39 & -0.55 \\
\hline H & 5000 & 210 & $<0.4$ & 160 & 17 & 0.76 \\
\hline
\end{tabular}

Factor tox are the scores of the sediments on the first principal component in a PCA using the contaminant concentrations ( $\mathrm{Cd}, \mathrm{Cu}, \mathrm{Zn}, \mathrm{Pb}, \Sigma \mathrm{PAHs})$, see Section 2.

\section{Results}

\subsection{Food}

A high survival was observed for animals feeding on $U$. dioica powder, green alga, $N$. perminuta and the combination of $N$. perminuta and Urtica (Fig. 2). Only Tetraphyll caused a significantly $(p<0.05)$ lower survival. Growth in the presence of $N$. perminuta and the combination of $N$. perminuta and $U$. dioica was significantly $(p<0.05)$ higher than for the other food sources, the latter sustaining the best growth. The combination of a $N$. perminuta and $U$. dioica was therefore chosen as food source for both cultures and experiments. 


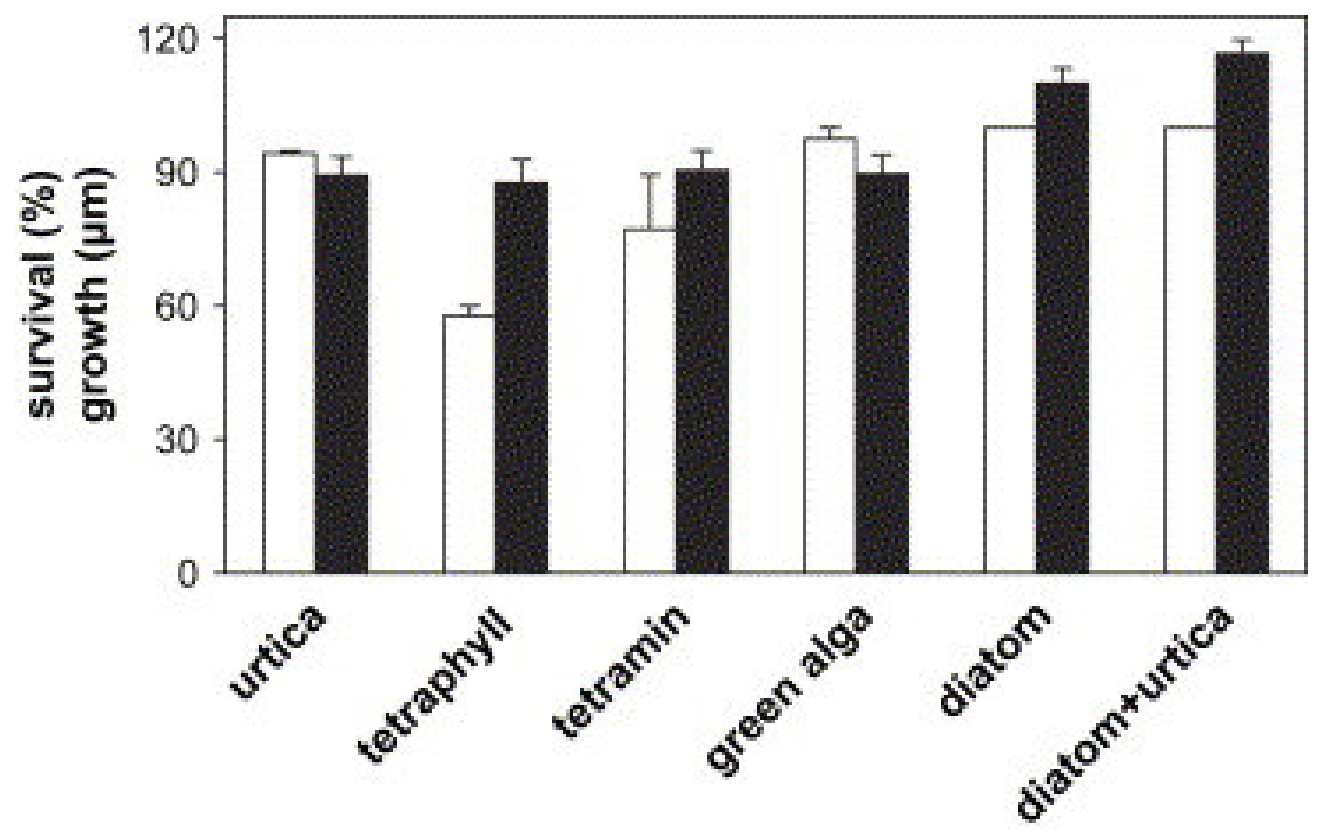

Fig. 2. Survival (white bars) and growth (black bars) of C. sphaericus after $96 \mathrm{~h}$, feeding on different food sources. Error bars represent standard errors.

\subsection{Temperature}

No significant differences were found for survival at temperatures between $5^{\circ} \mathrm{C}$ and $20^{\circ} \mathrm{C}$, but survival at $25^{\circ} \mathrm{C}$ was much lower (Fig. 3). Developmental stage increased significantly $(p<0.05)$ with increasing temperature (Fig. 3) and therefore the most suitable temperature for chydorid toxicity test was considered to be $20^{\circ} \mathrm{C}$. Moreover, most standard toxicity tests are also performed at $20^{\circ} \mathrm{C}$ which facilitate comparisons.

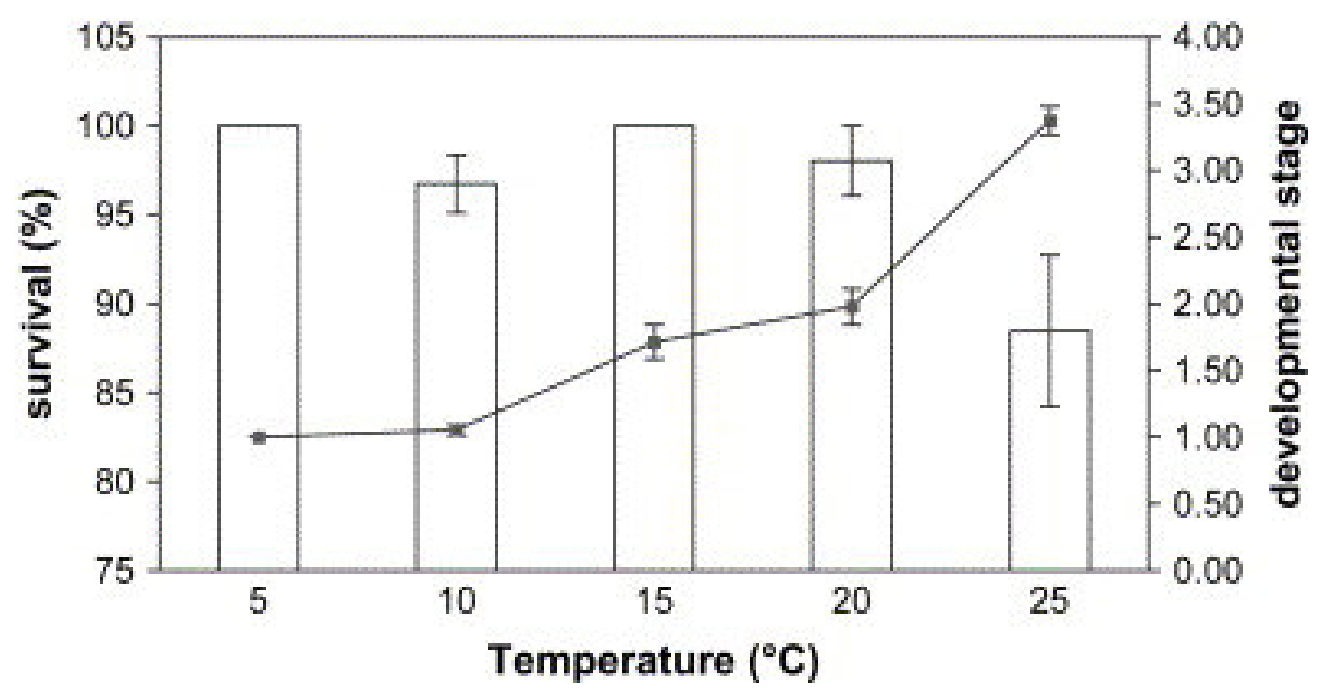

Fig. 3. Survival (bars) and developmental stage (line) of C. sphaericus after $96 \mathrm{~h}$ at five temperatures. Error bars represent standard errors. 


\section{3. $\mathrm{Cu}$ and $\mathrm{Cd}$ toxicity}

Control survival was above $90 \%$. Clear dose-response relationships were observed for survival, growth and development of chydorids exposed to copper or cadmium (Fig. 4). The corresponding $\mathrm{LC}_{50}$ and $\mathrm{EC}_{50}$ values are listed in Table 2. $C$. sphaericus responded differently to either metal. In the case of cadmium, the $\mathrm{EC}_{50}$ values for the sub-lethal endpoints growth and development were lower than the $\mathrm{LC}_{50}$. In contrast, for $\mathrm{Cu}$ the $\mathrm{LC}_{50}$ was lower than the $\mathrm{EC}_{50} \mathrm{~S}$, indicating that the some surviving animals were still able to develop.
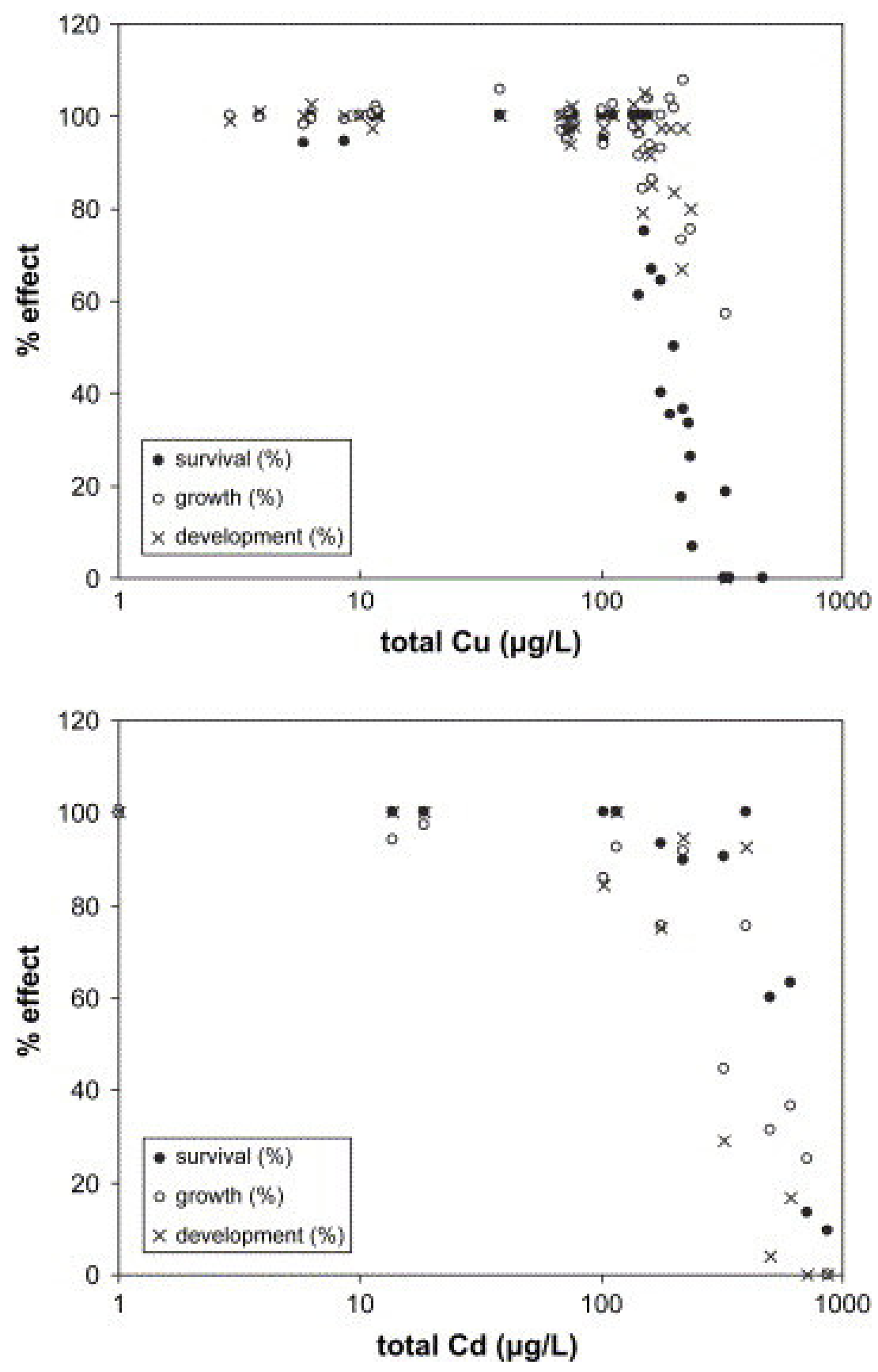

Fig. 4. Survival, growth and development of C. sphaericus after $96 \mathrm{~h}$ exposure to copper (top) and cadmium (bottom). 
Table 2.

Median effect concentrations for survival $\left(\mathrm{LC}_{50}\right)$ and growth and development $\left(E_{50}\right)$ for Chydorus sphaericus after $96 \mathrm{~h}$ of exposure to copper and cadmium (95\% confidence limits are given in parentheses)

\begin{tabular}{|l|l|l|l|}
\hline Metal & LC $_{\mathbf{5 0}}(\boldsymbol{\mu g} / \mathbf{L})$ & $\mathrm{EC}_{\mathbf{5 0}}$ growth $\mathbf{( \mu g / \mathbf { L } )}$ & $\mathrm{EC}_{\mathbf{5 0}}$ development $\mathbf{( \mu g / \mathbf { L } )}$ \\
\hline $\mathrm{Cu}$ & $191(184-198)$ & $358(303-413)$ & $258(240-276)$ \\
\hline $\mathrm{Cd}$ & $594(545-641)$ & $409(322-496)$ & $359(251-467)$ \\
\hline
\end{tabular}

\subsection{Ammonia toxicity}

Control survival was at least $80 \%$. Clear dose-response relationships were observed for survival of chydorids exposed to ammonia, either expressed as total ammonia or as $\mathrm{NH}_{3}$ (Fig. 5). The corresponding $\mathrm{LC}_{50}$ and $\mathrm{LC}_{10}$ values are listed in Table 3. Since ammonia is one of the most frequently occurring confounding factors in sediment toxicity tests the present effect concentrations should be used as a reference for sediment toxicity tests with $C$. sphaericus.
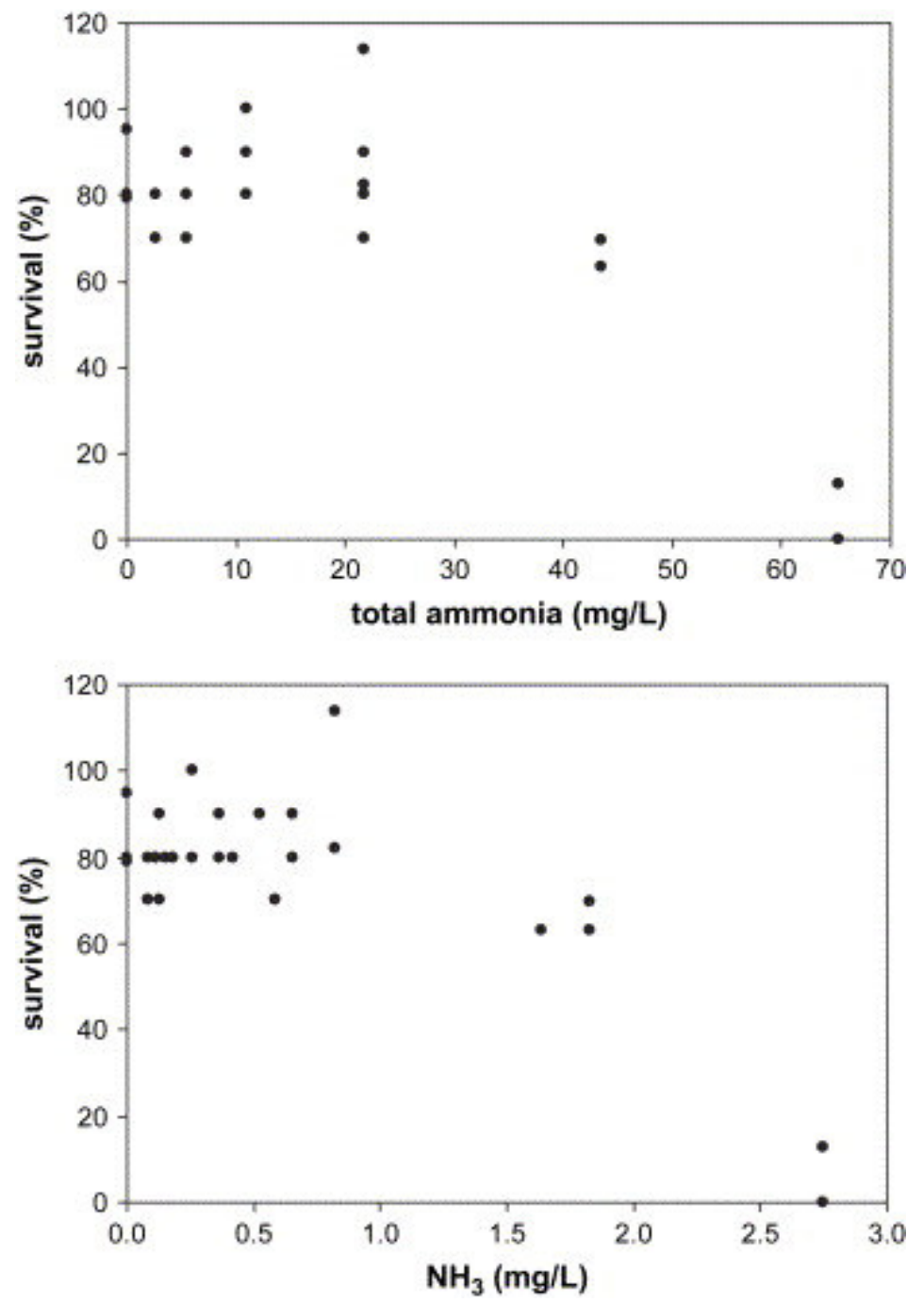

Fig. 5. Survival of $C$. sphaericus after $96 \mathrm{~h}$ exposure to ammonia, expressed as total ammonia (top) and as $\mathrm{NH}_{3}$ (bottom). 
Table 3.

$\mathrm{LC}_{10}$ and $\mathrm{LC}_{50}$ values for Chydorus sphaericus after $96 \mathrm{~h}$ of exposure to ammonia at $\mathrm{pH}$ 8, expressed as total ammonia and as $\mathrm{NH}_{3}$ (95\% confidence limits are given in parentheses)

\begin{tabular}{|l|l|l|}
\hline & $\mathbf{L C}_{\mathbf{1 0}} \mathbf{( m g / L )}$ & $\mathbf{L C}_{\mathbf{5 0}}$ ( $\left.\mathbf{m g} / \mathbf{L}\right)$ \\
\hline Ammonia & $36(26-49)$ & $46(42-51)$ \\
\hline $\mathrm{NH}_{3}$ & $1.38(1.04-1.85)$ & $1.90(1.70-2.13)$ \\
\hline
\end{tabular}

\subsection{Sediment toxicity}

Control survival was at least $80 \%$. The field collected sediments caused a clear response gradient (Fig. 6) since five samples, $\mathrm{C}$ and $\mathrm{E}-\mathrm{H}$, caused a significant $(p<0.05)$ lower survival than in the controls and the sediments $\mathrm{G}$ and $\mathrm{H}$ caused even complete mortality. In the samples A-D enough larvae survived the $96 \mathrm{~h}$ exposure to measure growth, which was significantly $(p<0.05)$ lower than in the corresponding controls. There was, however, no significant $(p>0.05)$ correlation between survival (Fig. 6) and the factor tox (Table 1). This was mainly caused by sample G, which contained relatively low concentrations of the measured toxicants, but caused complete mortality. Omitting this sediment from the statistical analysis revealed a significant negative correlation $(p<0.05$; $r=-0.76$ ) between survival and the factor tox. The $\mathrm{NH}_{4}{ }^{+}$concentrations were below detection limits in all treatments.

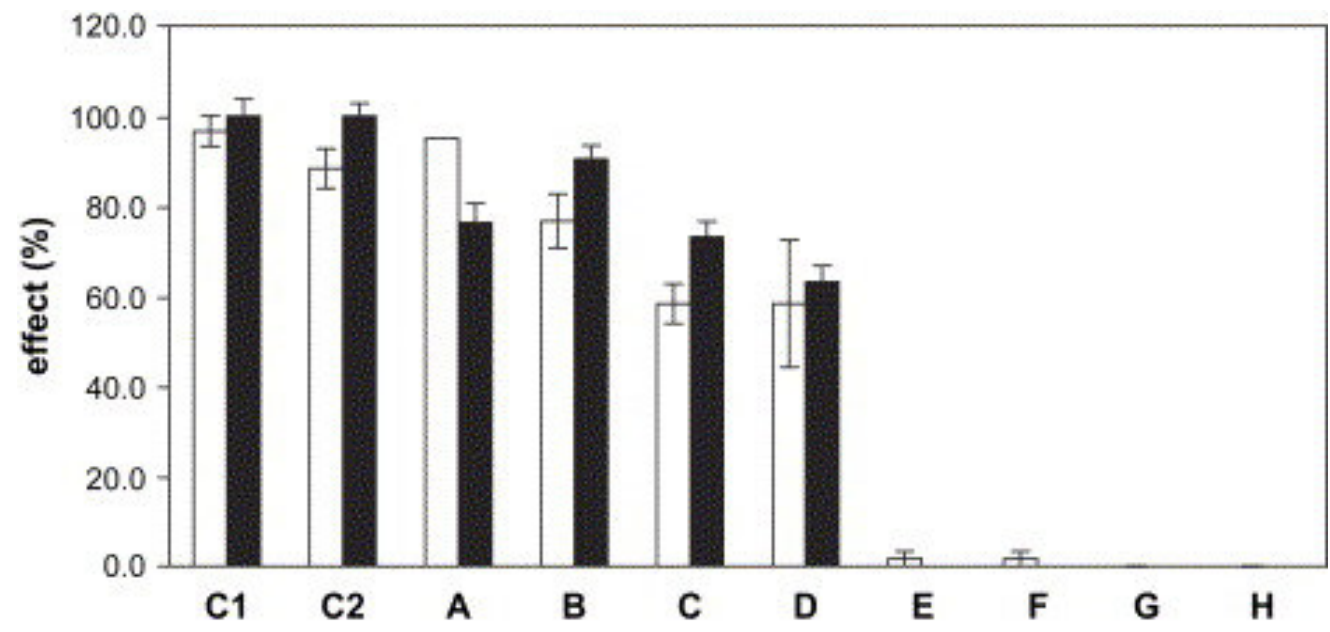

Fig. 6. Survival (white bars) and growth (black bars) of C. sphaericus after $96 \mathrm{~h}$ exposure to sediments from the Wenumse Beek. A-H field samples, $\mathrm{C} 1$ water only control, C2 water and sand control. Error bars represent standard errors.

\section{Discussion}

The first step in the development of a sediment toxicity test using the benthic cladoceran C. sphaericus was to start a laboratory culture and optimize their performance under control conditions. The test species was easy to culture and high survival, growth and development were obtained when feeding the animals a mixture of $N$. perminuta and Urtica at $20^{\circ} \mathrm{C}$. As expected, developmental rate increased with increasing temperature, as observed previously for $C$. sphaericus (Keen, 1973, Bottrell, 1974, Meyers, 1984 and De Eyto and Irvine, 2001). At the highest tested temperature $\left(25^{\circ} \mathrm{C}\right)$ we found the highest developmental rate, but 
mortality also increased. Therefore the most suitable temperature for the chydorid toxicity test was considered to be $20^{\circ} \mathrm{C}$. The choice of this temperature facilitates comparisons, since most standard toxicity tests are also performed at $20^{\circ} \mathrm{C}$.

De Eyto and Irvine (2001) observed that $C$. sphaericus grew equally well on all the food types offered: algae, detritus or filtered pond water, and explained this by its generalistic mode of feeding. Our findings agree only partly with theirs. Indeed, C. sphaericus grew and developed well on all food types, yet significant better growth was obtained when feeding the animals a mixture of $N$. perminuta and Urtica.

The sensitivity of C. sphaericus (96 h LC 50 values of $594 \mu \mathrm{g} / \mathrm{L}$ and $191 \mu \mathrm{g} / \mathrm{L}$ for cadmium and copper, respectively) is similar to that of daphnids: Biesinger and Christensen (1972) found an $\mathrm{LC}_{50}$ for copper (48 h) for $D$. magna of $60 \mu \mathrm{g} / \mathrm{L}$, using softer water than the present study. Stuhlbacher et al. (1993) found LC 50 $(48 \mathrm{~h}$ ) values for cadmium for $D$. magna between 24.4 and $355 \mu \mathrm{g} / \mathrm{L}$, depending on clone and preconditioning. Schubauer-Berrigan and Dierkes (1993) found LC $_{50}$ values for Ceriodaphnia dubia for copper and cadmium to range from $9.5 \mu \mathrm{g} / \mathrm{L}$ to $500 \mu \mathrm{g} / \mathrm{L}$ and from $5 \mu \mathrm{g} / \mathrm{L}$ to $780 \mu \mathrm{g} / \mathrm{L}$, respectively. A major influence on the $\mathrm{LC}_{50}$ values in their study was the $\mathrm{pH}$ of the medium.

Koivisto et al. (1992) and Bossuyt and Janssen (2005) reported lower $\mathrm{LC}_{50}$ values for copper for $C$. sphaericus $(7.6 \mu \mathrm{g} / \mathrm{L}$ and $20-38 \mu \mathrm{g} / \mathrm{L}$, respectively) than in the present study. However, Koivisto et al. (1992) gave green algae as food (Scenedesmus sp.) which is not optimal as observed in the present study, while Bossuyt and Janssen (2005) did not feed the animals at all. Here, the chydorids were fed a surplus of optimised food, which may have reduced the bioavailability of the metals as well as the sensitivity of the chydorids. However, when exposed to sediment bound toxicants, which was the purpose of the present test, chydorids may be exposed via several different exposure routes and Dekker et al. (2002) observed the effects of cadmium on Chydorus piger at relatively low concentrations in the sediment. The sensitivity of $C$. sphaericus to total ammonia ( $96 \mathrm{~h} \mathrm{LC}_{50}$ value of $46 \mathrm{mg} / \mathrm{L}$ ) is within the range reported for daphnids (25$189 \mathrm{mg} / \mathrm{L}$ ) (Postma et al., 2002).

Reinhold-Dudok van Heel and Den Besten (1999) and Lahr et al. (2003) concluded that the chronic $D$. magna reproduction test with pore water was the most sensitive standard test to monitor sediment toxicity. Yet, Lahr et al. (2003) also reported that the results of none of the tests correlated with the sediment pollution classes deduced from chemical analysis. One of the reasons for these discrepancies could be the use of pelagic test organisms exposed to pore water. Alternatively, exposing sediment inhabiting organisms to whole sediment samples allows testing in their natural habitat. This way, the organisms are exposed not only to toxicants in the pore water but also to sediment bound toxicants. This may alter toxicity, since Simpson and King (2005) demonstrated that the rate of copper accumulation and the mode of copper toxicity were different for dissolved and particulate phases. Consequently, the discrepancies between results from sediment toxicity tests and chemical analyses may be reduced. In the present study, exposing benthic cladocerans to whole sediment samples, indeed a significant negative correlation between survival and toxicant concentrations was observed (when one outlier was ignored).

In conclusion, the toxicity test developed in the present study using the benthic cladoceran C. sphaericus has several advantages, such as the ease of maintaining cultures and the small amounts of material and space needed for the cultures and 
experiments. The duration of the test is very short compared to other tests including reproduction, because the life cycle of $C$. sphaericus lasts only four days, compared to the seven days for D. magna (Tessier and Consolatti, 1989). These advantages may reduce test costs, making $C$. sphaericus a very suitable test species for routine laboratory sediment toxicity testing.

\section{Acknowledgements}

This research was supported by the Technology Foundation STW, project code ABI 4701. ARCADIS did the sediment sampling in the Wenumse Beek and performed the chemical analysis of these sediments.

\section{References}

Admiraal et al., 1993 W. Admiraal, G. Van der Velde, H. Smit and W.G. Cazemier, The rivers Rhine and Meuse in The Netherlands: present state and signs of ecological recovery, Hydrobiologia 265 (1993), pp. 97-128.

Beurskens et al., 1993 J.E.M. Beurskens, G.A.J. Mol, H.L. Barreveld, B. Vanmunster and H.J. Winkels, Geochronology of priority pollutants in a sedimentation area of the Rhine River, Environmental Toxicology and Chemistry 12 (1993), pp. 1549-1566.

Biesinger and Christensen, 1972 K.E. Biesinger and G.M. Christensen, Effects of various metals on survival, growth, reproduction and metabolism of Daphnia magna, Journal of the Fisheries Research Board of Canada 29 (1972), pp. 1691-1700.

Bossuyt and Janssen, 2005 B.T.A. Bossuyt and C.R. Janssen, Copper toxicity to different fieldcollected cladoceran species: intra- and inter-species sensitivity, Environmental Pollution 136 (2005), pp. $145-154$.

Bottrell, 1974 H.H. Bottrell, The relationship between temperature and duration of egg development in some epiphytic cladocera and copepoda from the River Thames, Reading, with a discussion of temperature functions, Oecologia 18 (1974), pp. 63-84.

Côté et al., 1998 C. Côté, C. Blaise, J.-R. Michaud, L. Ménard, S. Trottier, F. Gagné and R. Lifshitz, Comparison between microscale and whole-sediment assays for freshwater sediment toxicity assessment, Environmental Toxicology and Water Quality 13 (1998), pp. 93-110.

De Eyto and Irvine, $2001 \mathrm{E}$. De Eyto and K. Irvine, The response of three chydorid species to temperature, pH and food, Hydrobiologia 459 (2001), pp. 165-172.

Dekker et al., 2002 T. Dekker, O.E. Krips and W. Admiraal, Life history changes in the benthic cladoceran Chydorus piger induced by low concentrations of sediment-bound cadmium, Aquatic Toxicology 56 (2002), pp. 93-101.

Duigan and Kovach, 1991 C.A. Duigan and W.L. Kovach, A study of the distribution and ecology of littoral freshwater chydorid (Crustacia, Cladocera) communities in Ireland using multivariate analysis, Journal of Biogeography 18 (1991), pp. 267-280.

Elendt, 1990 B.P. Elendt, Selenium deficiency in crustacea: an ultrastructural approach to antennal damage in Daphnia magna Straus, Protoplasma 154 (1990), pp. 25-33. Full Text via CrossRef

Emmerson et al., 1975 K. Emmerson, R.C. Russo, R.E. Lund and R.V. Thurston, Aqueous ammonia equilibrium calculations: effect of $\mathrm{pH}$ and temperature, Journal of the Fisheries Research Board of Canada 32 (1975), pp. 2379-2383.

Fryer, 1995 G. Fryer, Crustacean diversity in relation to the size of water bodies: some facts and problems, Freshwater Biology 15 (1995), pp. 347-361.

Haanstra et al., 1985 L. Haanstra, P. Doelman and J.H. Oude Voshaar, The use of sigmoidal dose response curves in soil ecotoxicological research, Plant and Soil 84 (1985), pp. 293-297.

Hann and Zrum, 1997 B.J. Hann and L. Zrum, Littoral microcrustaceans (Cladocera, Copepoda) in a prairie coastal wetland: seasonal abundance and community structure, Hydrobiologia 357 (1997), pp. 37-52.

Keen, 1973 R. Keen, A probabilistic approach to the dynamics of natural populations of the Chydoridae (Cladocera, Crustacea), Ecology 54 (1973), pp. 524-534.

Keen, 1979 R. Keen, Effects of fluctuating temperature on duration of egg development of Chydorus sphaericus (Cladocera, Crustacea), Journal of Thermal Biology 4 (1979), pp. 5-8. 
Kluttgen and Ratte, 1994 B. Kluttgen and H.T. Ratte, Effects of different food doses on cadmium toxicity to Daphnia magna, Environmental Toxicology and Chemistry 13 (1994), pp. 1619-1627.

Koelmans and Moermond, 2000 A.A. Koelmans and C.T.A. Moermond, Stofstroom-analyse, Zware metalen, PCBs en PAKs in uiterwaardplassen. TO Vastlegging nulsituatie, Wageningen Agricultural University, Wageningen, The Netherlands (2000) (Report).

Koivisto et al., 1992 S. Koivisto, M. Ketola and M. Walls, Comparison of five cladoceran species in short- and long-term copper exposure, Hydrobiologia 248 (1992), pp. 125-136.

Lahr et al., 2003 J. Lahr, J.L. Maas-Diepenveen, S.C. Stuijfzand, P.E.G. Leonards, J.M. Druke, S. Lücker, A. Espeldoorn, L.C.M. Kerkum, L.L.P. van Stee and A.J. Hendriks, Responses in sediment bioassays used in the Netherlands: can observed toxicity be explained by routinely monitored priority pollutants?, Water Research 37 (2003), pp. 1691-1710.

Mark and Solbé, 1998 U. Mark and J. Solbé, Analysis of the ecetoc aquatic toxicity (EAT) database V the relevance of Daphnia magna as a representative test species, Chemosphere 36 (1998), pp. 155166.

Meyers, 1984 D.G. Meyers, Egg development of a chydorid cladoceran, Chydorus sphaericus, exposed to constant and alternating temperatures: significance to secondary productivity in fresh waters, Ecology 65 (1984), pp. 309-320.

Nebeker et al., 1986 A.V. Nebeker, M.A. Cairns, S.T. Onjukka and R.H. Titus, Effect of age on sensitivity of Daphnia magna to cadmium, copper and cyanazine, Environmental Toxicology and Chemistry 5 (1986), pp. 527-530.

Postma et al., 2002 J.F. Postma, S. de Valk, M. Dubbeldam, J.L. Maas, M. Tonkes, C.A. Schipper and B.J. Kater, Confounding factors in bioassays with freshwater and marine organisms, Ecotoxicology and Environmental Safety 53 (2002), pp. 226-237.

Reinhold-Dudok van Heel and Den Besten, 1999 H.C. Reinhold-Dudok van Heel and P.J. Den Besten, The relation between macroinvertebrate assemblages in the Rhine-Meuse delta (The Netherlands) and sediment quality, Aquatic Ecosystem Health Management 1999 (1999) (2), pp. 19-38.

Robertson, 1988 A.L. Robertson, Life histories of some species of Chydoridae, (Cladocera: Crustacea), Freshwater Biology 20 (1988), pp. 75-84.

Rönnpagel et al., 1998 K. Rönnpagel, E. Janßen and W. Ahlf, Asking for the indicator function of bioassays evaluating soil contamination: are bioassay results reasonable surrogates of effects on soil microflora, Chemosphere 36 (1998), pp. 1291-1304.

Schubauer-Berrigan and Dierkes, 1993 M.K. Schubauer-Berrigan and J.R. Dierkes, pH-dependent toxicity of $\mathrm{Cd}, \mathrm{Cu}, \mathrm{Ni}, \mathrm{Pb}$ and $\mathrm{Zn}$ to Ceriodaphnia dubia, Pimephales promelas, Hyalella azteca and Lumbriculus variegates, Environmental Toxicology and Chemistry 12 (1993), pp. 1261-1266.

Sibly et al., 1999 P.K. Sibly, D.A. Benoit, M.D. Balcer, G.L. Phipps, C.W. West, R.A. Hoke and G.T. Ankley, In situ bioassay chamber for assessment of sediment toxicity and bioaccumulation using benthic invertebrates, Environmental Toxicology and Chemistry 18 (1999), pp. 2325-2336.

Simpson and King, 2005 S.L. Simpson and C.K. King, Exposure-pathway models explain causality in whole-sediment toxicity tests, Environmental Science and Technology 39 (2005), pp. 837-843.

Sokal and Rohlf, 1995 R.R. Sokal and F.J. Rohlf, Biometry (third ed.), W.H. Freeman and Company, New York (1995).

Stuhlbacher et al., 1993 A. Stuhlbacher, M.C. Bradley, C. Naylor and P. Calow, Variation in the development of cadmium resistance in Daphnia magna Straus; effect of temperature, nutrition, age and genotype, Environmental Pollution 80 (1993), pp. 153-158.

Tessier and Consolatti, 1989 A.J. Tessier and N.L. Consolatti, Variation in offspring size in Daphnia and consequences for individual fitness, Oikos 56 (1989), pp. 269-276.

Van de Bund and Spaas, 1996 W.J. Van de Bund and S.J.H. Spaas, Benthic communities of exposed littoral sand-flats in eighteen Dutch lakes, Netherlands Journal of Aquatic Ecology 30 (1996), pp. 1520.

Whiteside et al., 1978 M.C. Whiteside, J.B. Williams and C.P. White, Seasonal abundance and pattern of chydorids, cladocera in mud and vegetative habitats, Ecology 59 (1978), pp. 1177-1188.

Williams, 1982 J.B. Williams, Temporal and spatial patterns of abundance of the Chydoridae (Cladocera) in Lake Itasca, Minnesota, Ecology 63 (1982), pp. 345-353. 